\title{
Dez anos de Comunicação \& Educação
}

Especialmente para este número, publicamos os principais momentos da mesa-redonda realizada em comemoração aos dez anos de Comunicação \& Educação. Foram reunidos ${ }^{1}$ os idealizadores e os colaboradores mais próximos da revista para um encontro memorável, no qual se registraram relatos sobre o projeto editorial da revista, sua proposta multidisciplinar que alia teoria e prática e o processo de produção em parceria com uma editora comercial. Os participantes também destacaram a importância da rede de colaboradores que se formou para dar sustentação à revista, bem como o papel de Comunicação \& Educação na consolidação de uma área de pesquisa e trabalho acadêmico que se desenvolveu em toda a América Latina a partir dos anos de 1990.

Por Roseli Fígaro

C \& E: Para dar início a nossa conversa, peço que todos se apresentem.

Maria Aparecida Baccega: Sou, atualmente, uma das editoras da revista Comunicação \& Educação, e a responsável editorial nos últimos dez anos. Tenho grande responsabilidade na criação da revista, não sozinha, mas dediquei-me muito a sua edição. Atualmente estou aposentada da Escola de Comunicações e Artes - ECA e trabalho como pesquisadora na Escola Superior de Propaganda e Marketing - ESPM. Na ECA, permaneço dando aulas no curso de especialização Gestão de Processos Comunicacionais ${ }^{2}$ e, agora, divido a edição da revista com a professora Maria Cristina Costa.

Maria Cristina Costa: Sou coordenadora do curso de especialização Gestão de Processos Comunicacionais e responsável pela publicação da revista Comunicação \& Educação. Responsabilidade que divido com a professora Maria Aparecida Baccega. Para mim esta é uma experiência nova, porque até então fui apenas colaboradora da revista, escrevendo artigos e fazendo sua divulgação para os alunos. Sempre achei que a revista Comunicação \& Educação tem grande contribuição a dar à sociedade.

1. A mesa-redonda realizou-se em 30 de abril de 2005, no Departamento de Comunicações e Artes da ECA-USP. Não puderam comparecer os convidados: prof. dr. Ismar de Oliveira Soares, Patrícia Carla dos Santos, Marluce Zacariotti, profa. dra. Elza Dias Pacheco e Izabel Leão.

2. Atualmente, Gestão da Comunicação. 


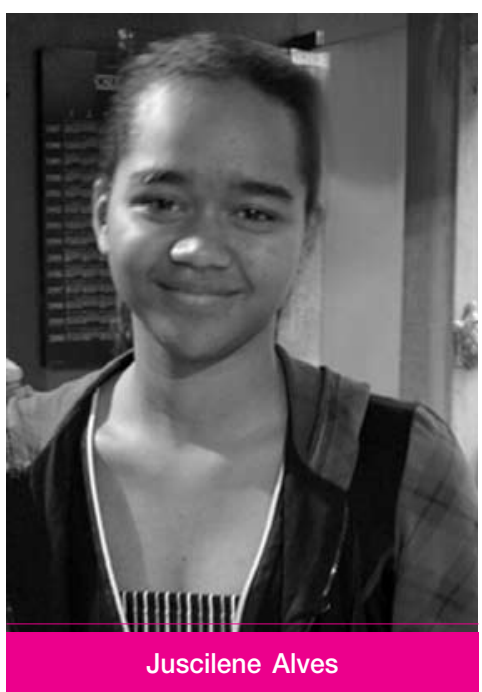

Juscilene Alves de Oliveira: Trabalho com a professora Baccega. Conheço a revista graças a ela.

Baccega: Juscilene é aluna do primeiro ano de publicidade da Faculdade Piratininga e minha auxiliar de pesquisa.

Roseli Fígaro: Atualmente sou professora da ECA e realizo pesquisas na área de comunicação e trabalho. Fui editora-executiva da revista Comunicação \& Educação do número 3 ao 26. A revista abriu um campo importante de reflexão e trouxe contribuição concreta para uma área de pesquisa que, já há alguns anos, vinha sendo desenvolvida por pesquisadores latino-americanos. No Brasil, a revista Comunicação \& Educação conseguiu consolidar uma proposta editorial que colaborou e colabora para o avanço dessa área de pesquisa.

Lucy Janja: Sou secretária da revista Comunicação \& Educação. Comecei em 1995, portanto faz dez anos. Tenho um amor muito grande por este trabalho. Sou responsável pela parte administrativa, embora tenha acompanhado todos os números da revista, vendo o trabalho dedicado a todos eles.

Adílson Citelli: Sou professor da Escola de Comunicações e Artes, trabalho na área de linguagem e comunicação e educação. Também estou na revista desde 1994, quando então discutíamos a criação desse veículo, pois identificávamos a falta de uma revista que pudesse divulgar os trabalhos nesse campo da comunicação e educação. Desde aquele momento, faço parte do Conselho Editorial e da Comissão de Publicação. Há um grande espaço para a revista progredir na medida em que tem um vetor, que é o contato com a academia,

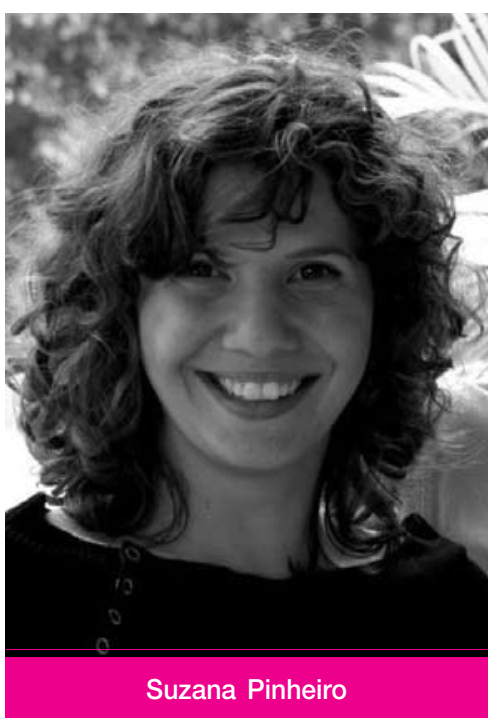
com textos resultantes de pesquisas, publicações nacionais e internacionais; e outro vetor mais de divulgação e de diálogo propriamente com os professores do ensino fundamental e do médio, e com aqueles que militam na área do ensino, da comunicação ou de outros segmentos da educação brasileira.

Suzana Pinheiro: Sou aluna da $15^{\mathrm{a}}$ turma do curso Gestão de Processos Comunicacionais e tenho como objeto de estudo de encerramento do curso a revista Comunicação \& Educação. Estou aqui para conhecer melhor aqueles que fizeram a revista, para estudá-la e poder organizar e propor um projeto de comunicação para sua divulgação. 
Eliane Perez Miraglia: Sou ex-aluna da $3^{\underline{a}}$ turma do curso Gestão de Processos Comunicacionais. Sou analista de comunicação da Fundação Cesp e também atuo na área de educação, como professora de comunicação empresarial nas Faculdades Integradas Torricelli. Trabalhei no último número da revista e pude perceber como o trabalho transdisciplinar proposto é muito bom para os alunos em sala de aula.

Consuelo Ivo: Também sou ex-aluna da 12ª turma do curso Gestão de Processos Comunicacionais. Fui convidada pela professora Cristina Costa a fazer um trabalho de relações institucionais para o curso e, recentemente, também para colaborar com a revista. A leitura que tenho feito das edições passadas vem demonstrando que a revista realmente possui uma importância muito grande para os estudos de comunicação e educação.

Maria Lourdes Motter: Sou professora da Escola de Comunicações e Artes, ligada a estudos de linguagem e, agora, com pesquisa em telenovela. Estou desde o início na revista Comunicação \& Educação; desde sua fase embrionária, em que se sonhava, se imaginava um modo de intervenção, um modo de fazer a academia se aproximar do trabalho do professor em sala de aula. As experiências que observávamos, feitas pelo próprio Ministério da Educação, pela Secretaria de Educação, não conseguiam frutificar em sala de aula e o professor continuava meio isolado em relação ao universo de novas possibilidades de trabalho com os meios de comunicação. Parece-me que esse foi o grande desafio para que nós, professores, sobretudo liderados pela professora Maria Aparecida Baccega, nos uníssemos em torno do sonho de produzir uma revista capaz de chegar até a linha de frente do trabalho educacional e, portanto, dar apoio e servir de referência para o trabalhador da educação. Estar aqui hoje, dez anos depois, chega a ser uma surpresa, porque se trabalha e se constrói com tanto cuidado e com tanta despretensão com relação ao tempo que é maravilhoso ver que a revista ganhou maturidade, respeito e ocupa um espaço fundamental no campo da educação. Sinto-me muito feliz de ter participado desde o início, fazendo parte do Conselho Editorial, da Comissão de Publicação, de ter acompanhado todos os altos e baixos pelos quais a revista passou, e de estarmos aqui hoje comemorando seus dez anos.

Sandra Caixeta: Estou no Departamento de Comunicações e Artes desde 1994. Acompanhei a implantação do Curso e também da revista. Pude ver muito trabalho dedicado a essa revista. Esse trabalho é o que garante a qualidade da publicação, reconhecida por todos.

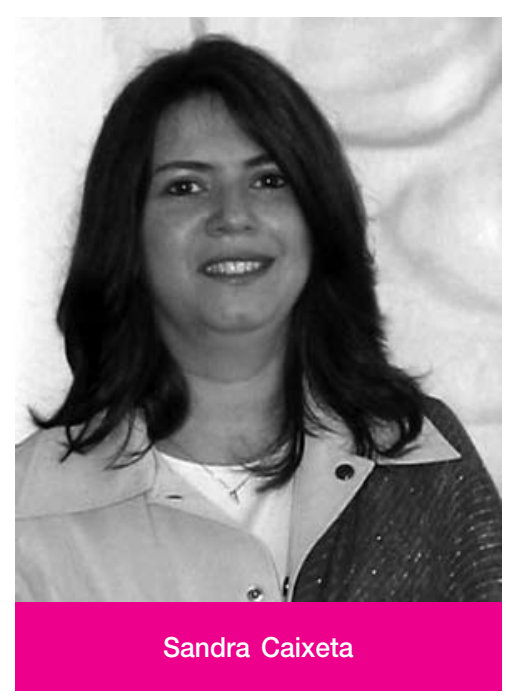


Kelly Regina Signorini: Estou trabalhando como secretária do curso de pós-graduação lato sensu Gestão de Processos Comunicacionais há cerca de cinco anos e tenho acompanhado o trabalho da revista através do curso.

C \& E: Nestes dez anos de existência a revista Comunicação \& Educação acumulou muita experiência e tem uma história a ser contada. Grande parte dos documentos dessa memória se perdeu com o incêndio que vitimou alguns departamentos da ECA em 2001. Como foi esse percurso da revista? Como nasce e se consolida a revista Comunicação \& Educação?

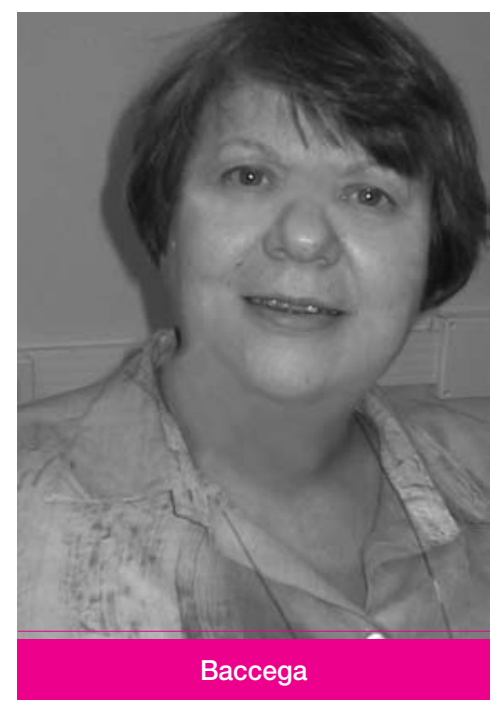

Baccega: Se o momento é de contar história, quero contar como começamos. Falo do ponto de vista do curso Gestão de Processos Comunicacionais e do ponto de vista de quem era chefe do Departamento naquele momento, no caso, eu mesma. $\mathrm{O}$ Departamento de Comunicações e Artes - CCA sempre se caracterizou por ser um departamento teórico. Ele vem de um momento em que na ECA existia o curso básico. Nós, professores do departamento, éramos responsáveis pelos dois primeiros anos do curso de todos os alunos da Escola, incluindo os alunos de artes. Penso que os alunos eram mais bem formados. É claro que havia um impasse. Os alunos não entendiam que aquilo que eles estavam fazendo conosco era importante, porque qualquer jovem de 18 anos - isso é absolutamente normal - quer apertar parafuso, quer pegar uma câmera na mão. Ele acha que pegar a câmera na mão vai resolver o problema, quando na verdade para se ter uma câmera na mão é preciso ter uma idéia na cabeça. E para ter uma idéia na cabeça dois anos de fundamentação teórica ainda é muito pouco. A situação da ECA, e a divisão em feudos que a Escola sempre teve, estava cada vez mais exacerbada e, no início dos anos de 1990, ganhou a eleição o professor José Marques de Melo, com a proposta de dividir ainda mais a Escola. Assim, quero deixar isso claro, a ECA estava apoiando essa feudalização, que sempre existiu, e passou a ser oficial. Considerávamos, como consideramos até hoje, que os conteúdos dos anos básicos eram absolutamente indispensáveis à formação profissional dos alunos. Não achávamos, já naquele momento, que o tipo de formação que o CCA dava nada tinha a ver com o mercado, embora isso fosse a idéia corrente na Escola. Preparar para o mercado é resultado da formação que a USP dá, não é a preocupação primeira, para a qual se voltam as escolas particulares. O mercado sabe disso e está muito bem dividido. Assim, nós sempre consideramos que os conteúdos que dávamos no CCA - nós éramos professores vindos das áreas de Letras, de Sociologia, de Filosofia, de Matemática etc. -, eram indispensáveis ao profissional. Tínhamos uma relação com o mercado, mas não de submissão. Relação de intercâmbio. Defendendo esse ponto 
de vista, fizemos aqui um famoso seminário, por volta de 1992, com profissionais que estavam no mercado para que eles debatessem o que achavam importante para a formação do comunicador. Vieram pessoas extremamente importantes, entre as quais Clarice Herzog, então no auge da carreira de publicitária. Lembro-me de sua fala: "Olha, vocês nos mandem alunos com formação geral, ampla e sólida, porque em três meses lá na agência eu ensino o que eu quero. Agora, se vocês me mandam aluno sem essa formação geral, nem em dois anos eu vou conseguir ensinar o que eu quero". Ou seja, os profissionais vieram aqui e ratificaram o que pensávamos. Nós nos sentimos então fortalecidos e começamos a fazer planos - resolvemos montar um curso, que passou a ter o nome de Gestão de Processos Comunicacionais. Quisemos que ele fosse uma pós-graduação lato sensu para começar, mas tínhamos intenção de criar também uma graduação. $O$ curso foi rapidamente aprovado na Reitoria de Pós-graduação, pelas várias comissões. O projeto, classificado como muito bom, foi bastante elogiado. Quanto ao projeto de graduação, foi boicotado pela Escola durante meses. Fiquei brigando na Congregação, órgão máximo de direção da ECA. Na época eu era chefe do Departamento, e fiquei meses defendendo a idéia do curso, conforme decisão do conjunto dos professores do CCA, evidentemente sabendo que não ia levar a nada. Era uma questão de princípio. O Departamento passou a ter, então, dois cursos de pós-graduação: a pós-graduação stricto sensu e a pós-graduação lato sensu. Fato que exigiu de nossa parte propor a edição de uma revista, ou melhor, de duas revistas: uma para cada curso. Para fazer uma revista, precisa-se de verbas, de recursos. Evidentemente o CCA não dispunha deles, como até hoje não dispõe. O nosso percentual de recursos na divisão da Escola era, na época, de 1,5\%. Consegui aumentá-lo em 100\%, passando-o para 3\% do total dos recursos destinados pela Reitoria à Escola. Mas, ainda assim, esses recursos eram insuficientes para a edição de uma revista, que dirá de duas! Tínhamos que conseguir parceria. A primeira coisa que fiz foi um concurso para definirmos o projeto gráfico das revistas. Um concurso com a participação de alunos da USP, não só da ECA. Chegaram vários projetos, havia prêmio em dinheiro. Lembro-me de que montamos uma equipe muito boa para avaliação dos projetos. Eram os melhores profissionais de design da cidade e vieram todos na base da amizade; ninguém ganhou nada, obviamente. Foi escolhido o primeiro projeto, o da pós-graduação stricto sensu. Foi feito pelos alunos da FAU... um projeto maravilhoso. Em segundo lugar, ganhou o projeto, também muito bonito, de alunos da ECA. Fomos então batalhar as parcerias pensando nas revistas. Tínhamos a prioridade da revista da pós-graduação stricto sensu. A segunda revista, a de lato sensu, seria uma revista do curso de Gestão, na área de comunicação e educação. Fomos procurar parceria para financiar as revistas. Parceria se busca com parceiros, com os amigos, porque ninguém vai financiar uma revista acadêmica, já que não dá dinheiro. Lá fui eu com os dois projetos debaixo do braço a várias editoras. Consegui ser ouvida por vários amigos. Só um conseguiu resultado, meu amigo Sérgio Couto, que trabalhava na Editora Moderna; deve-se 
a ele o fato de a revista ter-se iniciado. Em nossa conversa, ele nos disse que a revista de pós-graduação sctrito sensu não tinha nada a ver com a Editora Moderna, mas que Comunicação \& Educação, sim. Então, a Editora Moderna acolheu o projeto. Nunca conseguimos parceria para a revista da pós-graduação stricto sensu, nunca tivemos dinheiro da USP nem da pós-graduação para fazer essa revista. Assim, esquecemos o projeto dos alunos da FAU. Queimou-se no incêndio em 2001, e nada resta desta história, a não ser a memória. A revista Comunicação \& Educação começou, então, graças ao Sérgio Couto, que fez questão de acentuar que a Editora Moderna aceitava fazer a revista porque eu era a responsável, e eles conheciam meu texto e meu trabalho. Para eles era fundamental que o texto da revista fosse acessível aos professores da rede de ensino fundamental e médio. Não uma Vulgata. Um conteúdo com qualidade acadêmica, mas com texto claro, acessível, capaz de ser auto-explicativo. O desafio sempre foi grande. Batalhamos muito. $O$ texto da revista tem sido seu ponto alto durante todo esse tempo. Uma vitória! A revista tem periodicidade quadrimestral, são três por ano. O projeto foi desenvolvido pela Moderna até o número 15, ou seja, durante cinco anos. No número 16, passamos para a Editora Segmento. Edmílson Cardial, diretor, aceitou o projeto pensando na possível publicidade. Pode-se colocar publicidade em revista acadêmica, dependendo do produto que se divulga. Ficamos com a Segmento até o número 21. Para a número 22, nossa nova parceira foi a Editora Salesiana, que fez a revista do número 22 ao 27, quando terminou o contrato. Para que se entenda melhor como eram esses contratos de parceria, gostaria de dizer que além de não terem lucro, porque não tinham mesmo, as editoras pagavam mensalmente uma profissional para a revista. E o curso arcava com a tradução, os serviços de secretaria, correio, material de consumo etc., enquanto as editoras parceiras davam condições para que a revista fosse toda editada por nós, aqui na escola. E, a partir do final de 2003, não conseguimos mais isso. Este ano, 2005, a professora Cristina falou com a Editora Paulinas, que aceitou fazer a revista, não exatamente do modo como fazíamos, mas estamos nos adaptando. A revista saiu e está muito bonita, vocês devem têla visto. Adotamos agora a numeração por volume, ou seja, este é o número 3 do ano X. A Editora Paulinas tem profissionais de nível elevadíssimo e, enfim, as coisas estão indo bem. Uma outra coisa, antes de passar a palavra, é que sempre encarei o campo de comunicação e educação como mais abrangente do que a idéia de se discutir sobre ter ou não ter tecnologia na escola. A carta de princípios da revista Comunicação \& Educação saiu no número 1. Mantivemos e mantemos essa carta de princípios. Ou seja, queremos mostrar para todo mundo que vivemos num mundo editado, e que é a partir desse mundo editado que construímos uma nova variável histórica, porque a que está aí não serve. O problema não é desligar ou não a televisão, não é saber se o professor vai usá-la ou não em sala de aula. Comunicação/educação abarca isso, mas não é apenas isso. É um campo no qual os cidadãos estão sendo formados, malformados, deformados ou conformados. Depende muito de saber o que está por trás do processo para se conhecer a edição e, a partir daí, formar seu ponto de vista. 


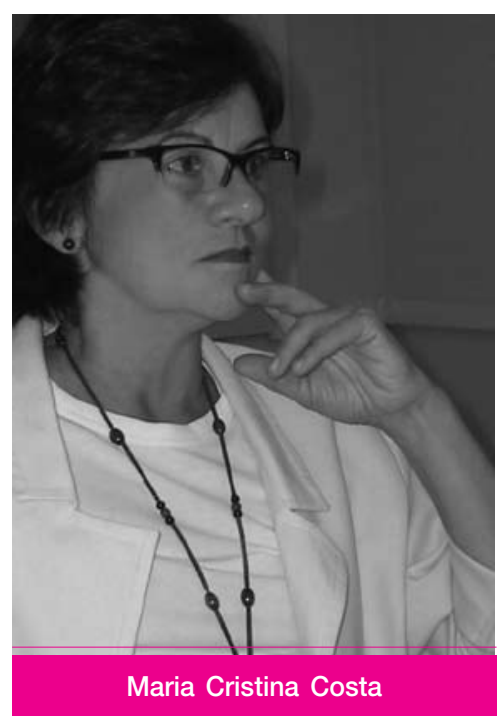

Maria Cristina Costa: No Brasil, principalmente por conta da inflação, houve um tempo em que as editoras se davam ao luxo de ter por objetivo a divulgação da cultura. Porque com 50, 80\% de inflação, com os contratos de pagamento de direitos autorais determinando o pagamento três meses depois da venda, ou seis meses depois da venda, nenhum produto precisava dar lucro. E mesmo vendendo pouco, as editoras viviam razoavelmente bem, ganhando com investimentos de capital. A Editora Moderna usava a política de ter produtos para grande venda, porque algum título precisava vender bastante para que rendesse capital, a fim de investir em seu catálogo, garantindo qualidade ao selo da editora. Nessa época, estava trabalhando com a coleção "Qual é o Grilo", editada pela Moderna, e lembro-me bem disso. A transformação ocorrida no mercado editorial nestes dez anos realmente colocou um novo desafio. Hoje as editoras precisam vender as publicações. E temos também hoje o desafio de ter um produto para ser vendido. Concordo com a professora Baccega, o mercado não é um inimigo. Não acho que tudo que vende é porque é ruim, e tudo o que não vende é porque é bom. É preciso uma sintonia com esse mercado. Quando passei a coordenar o curso Gestão de Processos Comunicacionais e a professora Baccega me passou algumas responsabilidades, entre elas encontrar um parceiro para a revista, assumi o desafio com toda garra. Pensei na Editora Paulinas, porque as Paulinas são uma ordem religiosa, católica, que escolheu a comunicação como um modo de atuação na sociedade. Há três anos participo dos cursos do SEPAC, Serviço Pastoral da Comunicação. É um curso de alto nível, com professores da PUC e aqui da ECA; um curso lato sensu na área de comunicação. Portanto, as Paulinas têm trabalhado muito nessa área de comunicação e educação, comunicação e evangelização, e acharam interessante ter parceria conosco para a publicação da revista Comunicação \& Educação. Os desafios são manter a qualidade e conseguir, digamos, maior penetração junto ao público leitor, para poder realmente evidenciar a utilidade desta revista que, tenho certeza, é muito grande. O fato de a Editora Paulinas ser uma empresa de caráter religioso não atrapalha em nada a seriedade e a laicidade com que as responsáveis encaram o conhecimento e o trabalho editorial com nossa revista. Temos um bom futuro pela frente. Essa é minha contribuição para esta história.

Adílson Citelli: Só vou fazer alguns acréscimos, porque a professora Baccega já fez um histórico da revista e mostrou exatamente qual foi o pro-

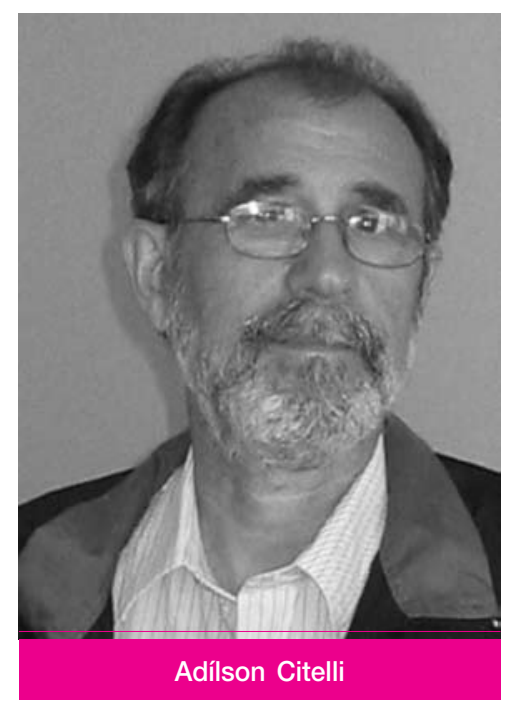


cesso que levou a sua elaboração. Quero apenas pontuar o seguinte. Primeiro, de fato, a revista Comunicação \& Educação acabou sendo a revista da ECA. A ECA tinha uma revista que se chamava Comunicações e Artes, e foi publicada até há alguns anos. Num certo momento, um grupo de professores assumiu essa revista: éramos o professor Jean-Claude Bernadet, a professora Jeanne Marie Machado de Freitas e eu. Nós refizemos o projeto que durou três ou quatro números e desapareceu também no pó do tempo. Reapareceu alguns anos depois numa espécie de apostila e desapareceu de novo. A pós-graduação não tem revista. Deve-se a isso o fato de muita gente se referir à revista Comunicação \& Educação como a revista da ECA. Ela virou a revista da ECA, porque a instituição não tem uma publicação com a penetração e o respeito que a revista Comunicação \& Educação adquiriu. Em segundo lugar, é bom lembrar que nesse momento histórico de implantação da revista, nós tínhamos conversado muito, mas de fato quem foi pegar o touro à unha foi a professora Baccega. Ela particularmente se empenhou muito e de forma voluntariosa e generosa com relação a esse tema. Foi à luta, traduzindo o anseio de algumas pessoas que queriam criar esse órgão de comunicação, que era ao mesmo tempo do curso Gestão de Processos Comunicacionais e da ECA. E evidentemente tínhamos, naquele início de 1994, os nossos objetivos, de grupo de professores da ECA que acreditavam numa determinada perspectiva de proposta de ensino. Queríamos dizer coisas com relação à educação, com relação a uma visão da comunicação. A revista constituiu uma tentativa de responder a essa desagregação da Escola, já historiada pela professora Baccega. A revista era aberta. Incluímos no Conselho Editorial colegas de vários departamentos. Enquanto a Escola falava em se separar, nós fazíamos uma revista que tentava reunir colegas de outros departamentos. Havia um objetivo claro. Nós estávamos dizendo para a Escola que discordávamos de um tipo de concepção atomizada, fato que levou a ECA à situação que está hoje. A revista surge nesse contexto. O CCA não conseguia fazer progredir os seus projetos. Nessa época, eu era o representante na Comissão de Graduação e no Conselho Técnico Administrativo - CTA; realizava a ligação das discussões dos projetos do departamento com o CTA e com a Comissão de Graduação e havia uma completa má vontade de fazer progredir qualquer coisa que viesse do CCA. Produzimos aqui vários ensaios, chegamos a realizar vários projetos. A própria forma do curso Gestão de Processos Comunicacionais foi uma resposta a esse isolamento. Era uma maneira de formar uma certa unidade entre os professores do departamento. Naquele momento, todos os professores do departamento participavam. O curso tinha uma característica muito própria, porque era diário; havia aula todos os dias à tarde, o que era uma espécie de sonho, manter um curso de pós-graduação lato sensu vespertino diário, voltado para o sistema público, sobretudo aos professores de ensino fundamental e médio. Enchíamos as classes. Depois com essa neoliberalização geral do País, as pessoas ficaram pobres, os professores perderam capacidade aquisitiva, não tinham mais nem como vir para a ECA, quanto mais fazer o curso. Quero dizer também que houve uma grande discussão, entre esse grupo de professores, sobre a gratuidade 
do curso Gestão. Muitos não queríamos o curso pago. Resistimos até onde foi possível. E, afinal, era uma resposta do departamento, que não conseguia fazer avançar sua proposta de graduação, porque a Escola não tinha interesse nesse sentido. O departamento de Comunicações e Artes vivia uma grande diáspora. Nós éramos 34 professores, ou algo em torno disso, e somos 17 hoje. A revista tem, desse ponto de vista, a característica de ser uma resposta política, isso é importante acentuar, de um grupo de professores que quer dizer o seguinte: é possível construir uma unidade na ECA. Muitos de nós fomos procurados, digamos assim, recrutados para irmos para outros departamentos. Alguns de nós achamos que não era o caso. Nosso objetivo era a criação de alternativas para o próprio departamento, e a tentativa de produzir um veículo de comunicação que a ECA paradoxalmente não possuía. Ou seja, uma publicação com periodicidade e com profunda vinculação com a sociedade. Tanto é que a revista Comunicação \& Educação chegou a ter um cadastro de três mil assinantes, o que é um número surpreendente para uma publicação acadêmica, num país como o nosso. Há um conjunto de elementos nesse balanço que não deve ser esquecido. A revista Comunicação \& Educação surgiu num contexto específico, também com pessoas que queriam discutir a comunicação e a educação num patamar que não aquele que a ECA estava imprimindo naquele momento, que era exatamente a construção de cursos basicamente profissionalizantes, no sentido não muito positivo. Brincávamos que, para o que se estava fazendo aqui, o Senac resolvia o assunto. Não era preciso gastar dinheiro público com isso. Era uma confusão que existe ainda. Esse registro é importante: a idéia de que todo o percurso da revista tem uma origem histórica está inserida no fervilhar de idéias e posições e debates que a ECA vivia naquele momento. Demos uma resposta objetiva para isso, porque ela está aqui. Tivemos uma pequena crise e, também com os esforços da professora Cristina, conseguimos outro parceiro e a revista existe. Já o modelo proposto para a Escola dez anos atrás está completamente detonado. Estamos correndo para recuperar o prejuízo que nos causa. E é tão grande que parte desse detonar, repercutiu na pós-graduação, e a Capes deu nota três para a ECA. Esta é uma nota absolutamente constrangedora para vários de nós que temos atuação na pós-graduação da ECA, em termos de trabalho, de pesquisa etc. É absolutamente constrangedor. A nota é um produto da história que está aí. Quanto à revista, agora com a injeção de ânimo novo dada pela professora Cristina e a parceria com a Editora Paulinas, tenho certeza, iremos progredir. Fora disso iremos ficando sem alternativas, porque o mercado editorial mudou completamente em dez anos. As editoras no Brasil passaram por uma mudança muito grande com esse processo de internacionalização do mercado editorial. O produto que não é vendido em cinco anos sai do catálogo. Não estou nem discutindo o mérito da publicação. Às vezes há publicações importantíssimas que saem. E não se conseguem reimpressões e reedições.

Baccega: Sobre a divulgação, quero dizer que chegamos aos três mil assinantes fazendo muita divulgação por conta própria. Nossos professores iam a congressos levando a revista na bagagem. Carregavam quilos de material para divulgá-lo nos 
eventos de que participavam. Em todos os congressos de Comunicação, fazíamos questão de ter a revista. Era uma luta convencer as editoras da necessidade de montar uma banca nos eventos nacionais e internacionais de comunicação e de educação. Chegamos mesmo a fazer com que a Editora Moderna disponibilizasse uma pessoa para fazer divulgação nas faculdades particulares. Foi estabelecida uma parceria entre a revista e o jornal $O$ Estado de $S$. Paulo e, com isso, aumentamos muito nossa tiragem. Todo esforço de divulgação é necessário. Não adianta colocar a revista na vitrina e esperar que ela seja vendida. O resultado de todo esse trabalho também pode ser visto nas citações bibliográficas das dissertações e teses defendidas em todo o Brasil. Invariavelmente há um ou mais artigos citados. A revista conseguiu uma penetração acadêmica muito grande... acho que não estamos sabendo aproveitar devidamente todo esse capital.

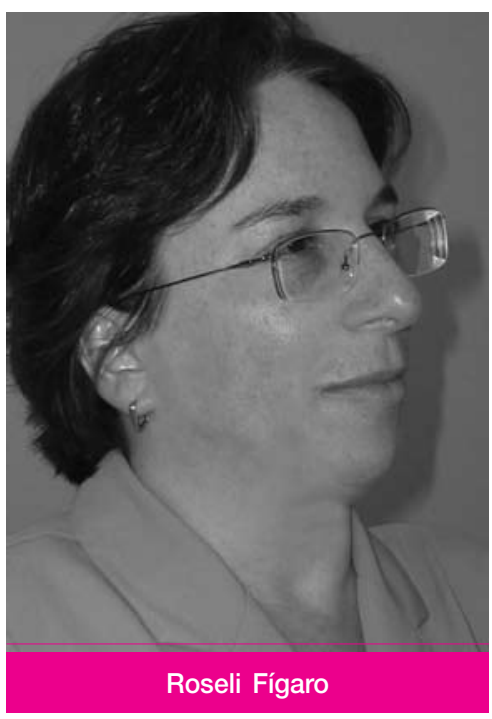

Roseli Fígaro: Do ponto de vista profissional, a experiência com Comunicação \& Educação foi um grande aprendizado. Minha formação é em jornalismo, e cheguei na revista como orientanda da professora Maria Aparecida Baccega. Terminado o mestrado, me dispus a auxiliar na elaboração da revista. Era a número 2, e permaneci na edição da Comunicação \& Educação até o número 26, sempre sob a direção e orientação da professora Baccega. Fazer a revista, além do envolvimento pessoal, intelectual, emocional, significa conceber um produto como este, nas condições em que estávamos - trabalhando aqui na universidade com uma pequena estrutura. Tínhamos, então, uma secretária, uma assistente editorial, eu, como editora executiva, e a professora Baccega como editora responsável e diretora editorial da revista. Éramos as responsáveis por colocar o produto editado nas mãos da Editora Moderna e fazer todo o acompanhamento para que ele chegasse, no prazo, aos leitores. Sempre prezamos muito as características do que é um veículo de comunicação. Uma revista é um produto que deve ter um público, um formato, uma cara, uma personalidade e uma periodicidade; que tem de ser respeitada. Ao contrário da maioria das revistas acadêmicas que, por conta da realidade que temos no país, não existe a periodicidade respeitada, Comunicação \& Educação, até a crise do número 27, com a saída da Editora Salesiana, nunca atrasou. Dizer isso parece uma coisa banal, mas torna-se um feito, levando-se em consideração as condições em que era produzida: uma equipe com quatro pessoas, sem dinheiro, sem infra-estrutura, com um computador velho, fazendo tudo e contando com a colaboração espontânea de colegas, ilustradores, fotógrafos, tradutores, conseguida gratuitamente. Construímos uma rede de colaboradores unidos pelo projeto maior relacionado à produção intelectual acadêmica e à universidade pública. A persistência e defesa dessa 
idéia são a força de um periódico. E a ECA não tem uma revista porque não temos unidade na diversidade. Um periódico para se sustentar precisa de uma linha editorial como nos grandes jornais que, apesar de todas as dificuldades financeiras, exibem uma coerência, que os faz serem grandes. Comunicação \& Educação tem personalidade, conseguiu manter sua periodicidade e, o mais importante, é fundada numa concepção de vida coletiva - tem uma idéia por trás, uma linha editorial, não é uma somatória de artigos. Quanto à produção, já registrei as dificuldades decorrentes da falta de infra-estrutura. Resta destacar os colaboradores, os autores que participaram da revista e o trabalho de jovens como a Patrícia Carla dos Santos, que foi nossa assistente editorial durante os últimos anos; uma pessoa muito competente que nós ajudamos a formar. Hoje está fazendo pós-graduação, é pesquisadora no Núcleo de Estudos da Violência e professora da escola pública. Quero salientar esse papel que a revista teve na formação de profissionais para a área editorial: Priscila Úrsula dos Santos, aluna da ECA, trabalhou conosco e é profissional do campo editorial; Fábio Nogueira foi nosso bolsista; Betina dos Santos Ruiz por vários meses trabalhou conosco; Jandira Queirós, brilhante estudante da FFLCH, trabalha com texto numa editora e foi formada por nós também; Tarcísio Alves, estudante de Letras, que veio para o jornalismo e faz pós-graduação nessa área, e foi nosso bolsista. No levantamento sobre a produção da revista até o número 26, temos 265 autores, dos quais 23 estrangeiros e 140 professores e pesquisadores de universidades. De professores de ensino fundamental e médio, tivemos 33 artigos. Fazer com que professores de sala de aula escrevam e vejam suas experiências publicadas é uma gratificação muito grande para nós. Temos artigos de profissionais da mídia, poetas, escritores, publicitários, jornalistas, radialistas, todos colaboradores da revista. Toda a riqueza aparece no nosso dia-a-dia. É muito comum alunos de graduação dizerem: "Fiz uma pesquisa na revista Comunicação \& Educação sobre o tema do meu trabalho, e encontrei 50 artigos. Como seleciono?”. A Videografia, seção de responsabilidade de Maria Ignês Carlos Magno, era muito procurada pelos professores de sala de aula, assim como a bibliografia sobre telenovela e os depoimentos. Mas, ao lado dessa colaboração estimulante e gratificante, passamos por muitas dificuldades técnicas e financeiras. A seção Entrevistas também rendeu grandes momentos. Certa vez, quando decidimos entrevistar o Jânio de Freitas, na sucursal da Folha, no Rio de Janeiro, Adílson disse: "Vocês não vão conseguir entrevistá-lo"; o Jair Borin disse: "O Jânio de Freitas não vai atendê-la, ele é muito fechado, ele não vai recebê-la”. Não sei se tive sorte, mas logo no primeiro contato consegui resposta positiva. Foi uma conversa muito agradável e instigante. Outra entrevista memorável aconteceu com o professor Jesús Martín-Barbero. Também tive a oportunidade de entrevistar o professor Armand Mattelart, no Congresso Internacional de Ciências da Comunicação, a Intercom, em Santos. Além de ter sido um prazer poder falar com ele, foi muito interessante. $\mathrm{O}$ processo de produção da revista espelha todo o cuidado que sempre tivemos com a seriedade e com a qualidade. Segundo o critério Qualis, todos os artigos de revistas científicas têm de passar pela efetividade da 
avaliação de pares. Desde o primeiro número, contamos com um Conselho Editorial seleto e todos os artigos eram avaliados por dois pareceristas que não tinham acesso à identificação do autor. O parecerista aprova, recomenda ou desaprova explicando porque, propondo alterações. Os critérios foram estabelecidos pelo Conselho e cada artigo chega às mãos do parecerista acompanhado dessas normas para a publicação. Dentre os aprovados, a editoria seleciona aqueles que de uma certa maneira dialogam entre si, convergindo e compondo temas. Era muito trabalho, mas esse processo que até hoje é respeitado garante a efetividade de avaliação dos pares a que fizemos referência.

Baccega: Tem uma coisa que ficou para trás e que é preciso ser dita. Desde o primeiro número, com a Moderna, ficou estabelecido que ninguém interferiria no processo editorial da revista. O trabalho das editoras se limitava ao trabalho gráfico. O sucesso da revista se deve a várias coisas, muitas delas já levantadas aqui. Mas, sobretudo, e não tenho medo de explicitar o sobretudo, à escritura do texto e ao fato de ela ter sido feita, inteira, sempre aqui. Isso é uma conquista que acho muito difícil, e nós obtivemos. Com relação às entrevistas, quero lembrar que a primeira entrevista é histórica, com o Duda Mendonça. Naquele momento, 1994, o Duda Mendonça queria fazer a campanha do Lula para a presidência e o PT não tinha deixado. Ele tinha mandado fazer, na Europa, uns bonequinhos que ele chegou a nos mostrar - eram uns bonecos pequenos, muito bonitos, que mostravam um Lula bom menino, bom velhinho. Com isso o Duda pretendia desmanchar aquele mal-estar que a sociedade tinha com relação ao Lula, fruto do preconceito. Ele nos mostrou também os jingles que havia feito para a campanha. Eram lindos, e essa entrevista é histórica. Depois, em 2002, ele pôde realizar a campanha e deu no que deu... o Lula está aí. Nós tivemos sempre essa preocupação em escolher para estar na revista aquilo que permanece, não o que é transitório. Isso é muito importante numa revista como esta.

Maria Lourdes Motter: A história da revista é história de convicção, de determinação, de coerência e de muito trabalho. Quando o Adílson diz que tínhamos de dar uma resposta para a Escola, o que se percebe é que a resistência com relação a essa base de conhecimento humanístico, a essa questão multidisciplinar, foi toda expressa na revista. A revista deu fisionomia ao nosso departamento. Foi como criar realmente um cartão de identidade para dizer: o departamento é isso! Quando falo em convicção, penso nessa certeza, nessa clareza de perceber que era isso realmente. Quer dizer, perceber o que éramos, o que queríamos continuar sendo, o que se pensava da educação naquele momento, olhando para

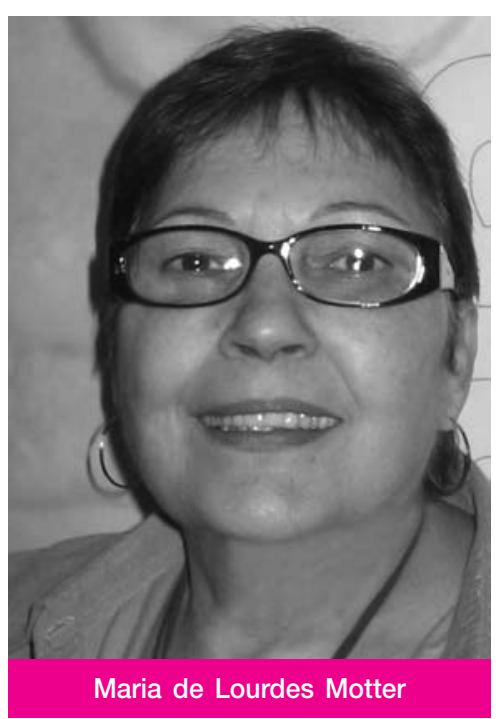


o futuro, para onde a educação deveria ir; a revista é expressão disso. Estou querendo dizer que a revista é expressão não só de um departamento, como também de uma visão da comunicação e de uma visão da educação. Quando ouvimos a Roseli falando das várias seções da revista, percebemos uma outra coerência fundamental. Além dessa coerência ideológica há esta de se unir a teoria à prática, o tempo todo, à reflexão. Mas isso é um problema... esbarra no modelo dominante, na medida em que se quer reunir uma teoria e uma prática, o discutir e o fazer, ou seja, unir um mundo que pensa e um mundo que faz. Essa foi a polêmica que levou a ECA a tal ruptura. O nosso departamento deixa de ser importante porque se privilegia o fazer, quando se sabe perfeitamente que o fazer sem a reflexão não vai a lugar nenhum, vai ser meramente reprodução. A revista tem um significado que transcende a tudo que poderíamos estar dizendo. A atualidade da revista é mais uma comprovação do acerto dessa busca de caminho, do acerto dessa filosofia que está em sua raiz. E é graças a isso tudo que ela tem essa pujança, essa força e a capacidade de resistência no transcorrer do tempo. O fazer artesanal também tem a ver com isso, porque é um grupo de pessoas que acredita naquilo que está fazendo e que faz, não delega, porque ela tem de continuar sendo a expressão do grupo, ser a expressão dessas idéias. Naturalmente, a grande idealizadora da revista, a grande entusiasta é a Baccega, em termos de liderança; em torno dessa liderança que todo o trabalho se desenvolve, que todo esse esforço acaba sendo concentrado. Por outro lado, chegamos aos dez anos sabendo de todas essas dificuldades. Colaboradores, professores, enfim, o grupo, que acredita na revista. Agora ela está num formato mais estético, um visual maravilhoso. Apesar de todos os problemas ela continua crescendo, ficando mais bonita, com atualidade e um olhar para o futuro. Essa vitalidade tem a ver exatamente com vontade, convicção, determinação, coerência e com o trabalho que o grupo vem desenvolvendo no curso nestes dez anos. Trabalho que não vejo esmorecer, porque parece que agora se cobra mais de nós e a disposição é de que todos dêem sua contribuição. Acredito que vamos continuar ainda, e quem sabe com dias bem melhores, enfim, em condições melhores de trabalho. O importante é que a idéia resiste e permanece; ela está aí.

Lucy Janja: Acompanhei todas as revistas, todas as dificuldades. Era uma produção trabalhosa, artesanal e coletiva, como já foi falado. Depois de pronta, divulgar, distribuir e passar release para todo mundo. A Roseli e a Baccega trabalhavam muito, demais. Às vezes até eu dava um socorro. Desejo muito sucesso para esta revista, porque sempre vimos todo esse empenho.

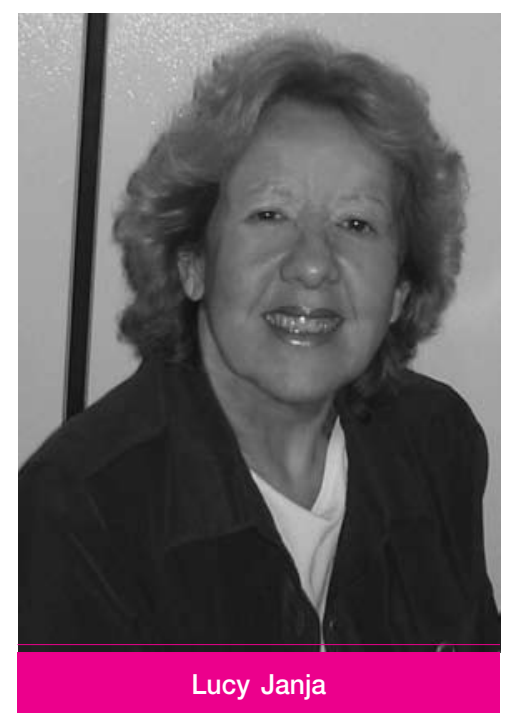


Sandra Caixeta: Queria falar um pouco sobre o orçamento. A infra-estrutura era precária, realmente o computador era lento, mas o dinheiro que sustentava essas atividades vinha do curso, pois o orçamento do departamento sempre foi muito pequeno. Trabalhamos com poucos recursos. Só dava para pagar um auxiliar; um outro, quando existia, era de bolsa-trabalho. Aí veio o incêndio que destruiu o departamento de Comunicações e Artes e queimou toda a estrutura e os equipamentos que tínhamos comprado com as economias de anos e anos do curso. De 2001 para cá, móveis e equipamentos que conseguimos foi por empréstimos ou doações. Conseguimos comprar, depois do incêndio, apenas duas impressoras e dois computadores. Com o incêndio sofreram o curso de Gestão e a revista, e, por isso, é um imenso prazer comemorar estes dez anos da revista.

Kelly Regina Sinhorini: Nestes cinco anos que estou trabalhando no curso Gestão de Processos Comunicacionais tenho acompanhado, convivido com todos, e vejo a importância da revista. A Sandra estava falando do incêndio no qual perdemos tudo; foi muito duro esse recomeço. Mas com força de vontade, com a experiência e o conhecimento de todos, nada parou, tudo continuou de uma outra forma, e com todos os problemas decorrentes. Também tenho orgulho muito grande de fazer parte deste grupo e contribuir, mesmo que seja de forma pequena, para o avanço do trabalho.
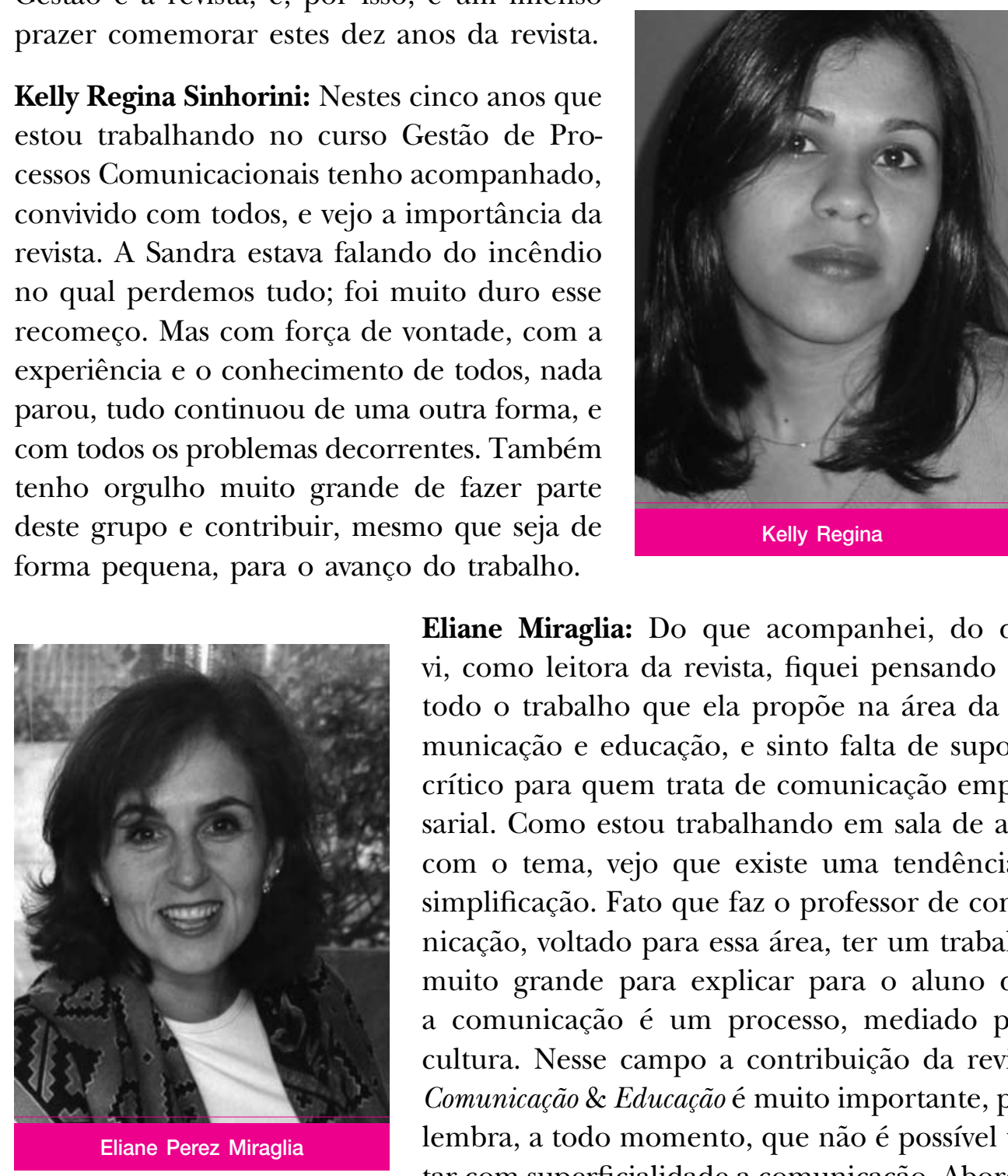

Eliane Miraglia: Do que acompanhei, do que vi, como leitora da revista, fiquei pensando em todo o trabalho que ela propõe na área da comunicação e educação, e sinto falta de suporte crítico para quem trata de comunicação empresarial. Como estou trabalhando em sala de aula com o tema, vejo que existe uma tendência à simplificação. Fato que faz o professor de comunicação, voltado para essa área, ter um trabalho muito grande para explicar para o aluno que a comunicação é um processo, mediado pela cultura. Nesse campo a contribuição da revista Comunicação \& Educação é muito importante, pois lembra, a todo momento, que não é possível tratar com superficialidade a comunicação. Abordar a comunicação exige preparo e reflexão. 


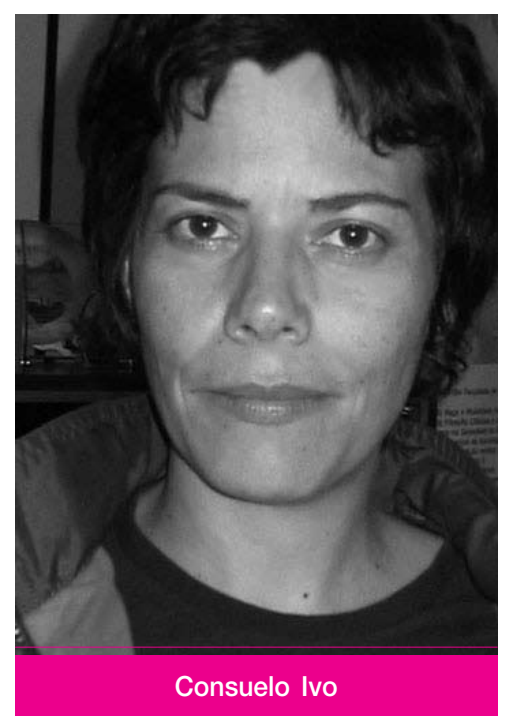

Consuelo Ivo: Vivo uma situação muito particular de alguém que foi aluna do curso de Gestão de Processos Comunicacionais e agora trabalha na revista. Percebo que muitos dos nossos alunos e dos nossos leitores são jovens. Eles vêm da faculdade com a idéia de que estão para ser eliminados do mercado, antes mesmo de entrar. $\mathrm{Na}$ conversa com eles, conto o que é o curso e como é feita a revista. E, invariavelmente, eles me dizem que é isso que vieram buscar. Precisam de teoria. É preciso contribuir para a construção de uma sólida base teórica para esses alunos e esses leitores. Na revista, sou aprendiz das artesãs. Tenho uma pequena experiência de trabalhar também nessa área editorial, mas é diferente. É um privilégio participar deste momento, acompanhar a revista neste ponto da sua história. E por falar em história, também gostaria de fazer aqui uma menção à atividade da Patrícia Carla, porque ela está sendo importantíssima para mim. Quando preciso de alguma informação, abro os arquivos, trabalhados pela Patrícia, e vejo que ela recuperou a memória da revista Comunicação \& Educação, após o incêndio, em um trabalho admirável, muito profissional. Tenho muito material para estudar e posso acompanhar melhor o ritmo desta nova fase da revista.

Juscilene Oliveira: O que tenho a dizer da revista é que no começo levei um choque quando a professora Baccega mostrou-me uma pilha de revistas, todas para eu ler. Perdi até noite de sono. As leituras que fiz foram fundamentais para escolher o curso que estou fazendo hoje, publicidade e propaganda. Foi muito importante, assim como estar ao lado da professora Baccega.

Roseli Fígaro: Antes de terminarmos, quero enfatizar a importância da divulgação da revista. Digo isso não só no sentido da memória, mas também a fim de contribuir para sua continuidade. No contrato de parceria sempre consta que a parte comercial e de venda da revista é responsabilidade da editora. No entanto, como sempre somos um produto diferente dentro das editoras, precisamos dar uma ajuda no que diz respeito à divulgação. O que fazer então? A Moderna, por exemplo, criou um setor de assinaturas e conseguimos três mil assinantes, do Amazonas ao Piauí e ao Rio Grande do Sul, no Brasil inteiro. Enfim, o que sempre fizemos foi uma ação de colaboração paralela, sempre dialogando com a editora, buscando a divulgação. Também fizemos um grande esforço para colocar a revista em livrarias. Isso é uma necessidade, porque as livrarias são vitrinas importantes. Este trabalho tem de continuar e temos certeza de que o sucesso será gratificante para todos os envolvidos no processo. 
Resumo: Principais momentos da mesaredonda realizada em comemoração aos dez anos da revista Comunicação \& Educação. Foram reunidos os idealizadores e os colaboradores mais próximos da revista para um encontro memorável, no qual se registraram relatos sobre o projeto editorial da revista, sua proposta multidisciplinar que alia teoria e prática e o processo de produção em parceria com editora comercial. Os participantes também destacaram a importância da rede de colaboradores que se formou para dar sustentação à revista, bem como o papel de Comunicação \& Educação na consolidação de uma área de pesquisa e trabalho acadêmico que se desenvolveu em toda a América Latina a partir dos anos 1990 .

Palavras-chave: Escola de Comunicações e Artes, Revista Comunicação \& Educação, projeto editorial, colaboradores, multidisciplinaridade, parceria editorial.
Abstract: Main moments of the round table on commemoration of the ten years of the journal Comunicação \& Educação. The idealizers and near cooperators were joined for a memorable meeting in which speeches on the publication editorial project, its multidisciplinary proposal that allies theory and practice, and the process of production in partnership with a commercial publishing house were registered. Participants also highlighted the importance of the net of cooperators that was formed to give sustainability to the journal, as well as the role of Comunicação \& Educação in the consolidation of an area of research and academic work that was developed in all Latin America since the 90's.

Keywords: Escola de Comunicações e Artes, Comunicação \& Educação, editorial project, cooperators, multidisciplinarity, editorial partnership. 